\title{
Catalytic oxidative decarboxylation of some arylacetic acids promoted by new Mn(III) and Fe(III) Schiff base complexes
}

\author{
Morteza Montazerozohori, ${ }^{\text {a* }}$ Mohammad Hossein Habibi, ${ }^{\text {b }}$ Leila Zamani-Fradonbe, \\ and Sayed Ali Reza Musavi ${ }^{a}$ \\ ${ }^{a}$ Department of Chemistry, Yasouj University, Yasouj 75918-74831, Iran \\ ${ }^{b}$ Department of Chemistry, Isfahan University, Isfahan, Iran \\ E-mail:mmzohori@mail.yu.ac.ir
}

\begin{abstract}
Bis(2-hydroxybenzene)phthaldiimine (BHBPDI) as a new quadridentate Schiff base ligand and its $\mathrm{Mn}$ (III) and Fe(III) complexes were synthesized and characterized by analytical and spectral data. The $\mathrm{Mn}$ (III) and $\mathrm{Fe}(\mathrm{III})$ complexes were employed as catalysts in the oxidative decarboxylation of a variety of arylacetic acids, using tetrabutylamonium periodate as oxidant. The reactions were carried out in dichloromethane at room temperature. Relatively rapid and efficient oxidative decarboxylation of arylacetic acids to corresponding aldehydes or ketones in good to high yields were observed in the presence of the system, $\left.\left[\mathrm{Mn}^{(\mathrm{IIII})}(\mathrm{BHBPDI})\right) \mathrm{Cl}\right] / \mathrm{imidazole} /(n-\mathrm{Bu})_{4} \mathrm{NIO}_{4}$. The $\mathrm{Fe}(\mathrm{III})$ analog system showed less catalytic activity at the same conditions.
\end{abstract}

Keywords: Schiff base, complex, catalyst, decarboxylation, iron(III), manganese(III)

\section{Introduction}

The catalytic oxidation of organic compounds such as alkenes, alkanes, alcohols, aldehydes and etc. using transition-metal complexes is an area of current interest. In this direction, synthetic organic ligands like porphyrin, phthalocyanine, and Schiff bases have been used in the development of synthetic metal complexes in order to mimic structural and spectroscopic features as well as the reactivity of an expressive number of metalloenzymes. ${ }^{1-8}$ Efficient homogeneous catalytic systems for oxidation of organic substrates based on porphyrinic compounds and manganese or iron Schiff-base complexes as promising catalysts have been reported. ${ }^{1,7,9-15}$ Decarboxylation processes play an important role in different areas of organic synthesis as well as in biochemical reactions. Several reports on this transformation by thermal, ${ }^{16-17}$ photochemical ${ }^{18-19}$ and catalytic methods ${ }^{20-21}$ have been reported. Such oxidative decarboxylation pathways have also been observed during drug metabolism in vivo. ${ }^{22,23}$ 
In continuation of our recently reports on the catalytic oxidation of organic compounds, ${ }^{24-26}$ here we report on the synthesis of bis(2-hydroxybenzene)phthaldiimine as a new quadridentate Schiff base ligand(BHBPDI) and its [ $\left.\mathrm{Mn}^{(\mathrm{III})}(\mathrm{BHBPDI}) \mathrm{Cl}\right]$ and $\left[\mathrm{Fe}^{(\mathrm{III})}(\mathrm{BHBPDI}) \mathrm{Cl}\right]$ complexes. In a second part, their promotion of the oxidative decarboxylation of a variety of arylacetic acids by these complexes is investigated (Scheme 1).

\section{Results and Discussion}

\section{Characterization of the Bis(2-hydroxybenzene)phthaldiimine (BHBPDI), $\left[\mathrm{Mn}^{(\mathrm{III})}(\mathrm{BHBPDI}) \mathrm{Cl}\right]$ and $\left[\mathrm{Fe}^{(\mathrm{III})}(\mathrm{BHBPDI}) \mathrm{Cl}\right]$}

The ligand (BHBPDI) was prepared by condensation of phthaldialdehyde and 2-aminophenol in a 1:2 molar ratio in ethanol under reflux. Elemental analysis, FT-IR and ${ }^{1}$ HNMR confirmed the synthesis of ligand.

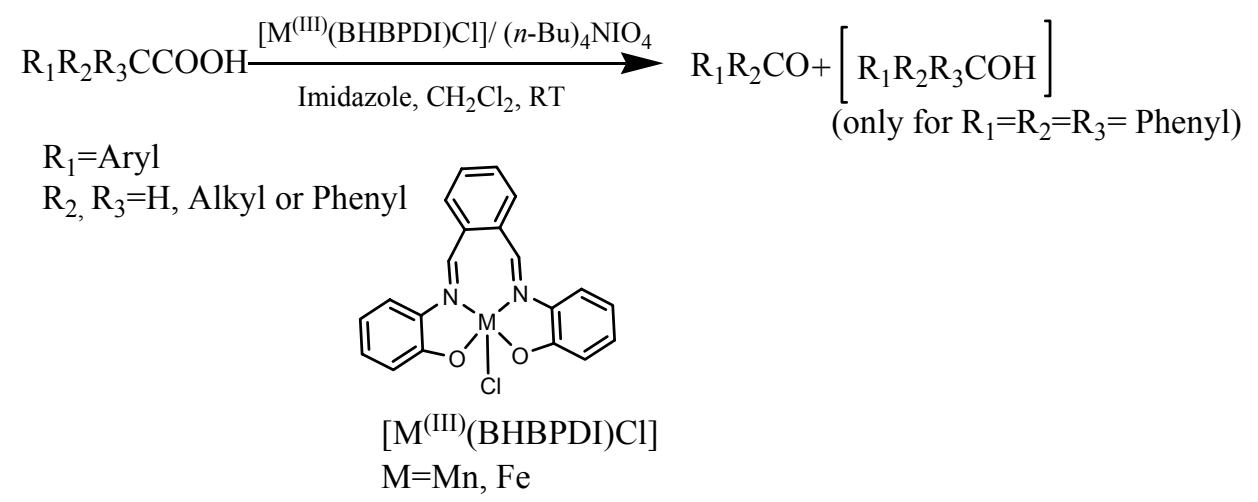

\section{Scheme 1}

Elimination of characteristic stretching frequencies of $-\mathrm{C}=\mathrm{O}$ of phthaldialdehyde at $1686 \mathrm{~cm}^{-1},-\mathrm{NH}_{2}$ and $-\mathrm{OH}$ of 2-aminophenol at $3375,3304 \mathrm{~cm}^{-1}$ and $2851 \mathrm{~cm}^{-1}$ (very broad), and appearance of strong stretching frequencies at 1634 and $3306 \mathrm{~cm}^{-1}$ assigned to $-\mathrm{C}=\mathrm{N}$ and $-\mathrm{OH}$ are in good agreement with the ligand structure. The ${ }^{1} \mathrm{HNMR}$ spectrum of the ligand in dimethylsolfuxide- $\mathrm{d}_{6}$ solution gives signals at 10.22 and 8.88 (two broad signal, $2 \mathrm{H}$ ) for two $-\mathrm{OH}$ groups of the ligand, $7.57(\mathrm{~m}, 4 \mathrm{H})$ for phthaldiimine ring and $7.16(\mathrm{~m}, 2 \mathrm{H},-\mathrm{CH}=\mathrm{N}), 6.93(\mathrm{~m}$, $2 \mathrm{H}), 6.61(\mathrm{~m}, 2 \mathrm{H})$ and $6.35(\mathrm{~m}, 4 \mathrm{H}) \mathrm{ppm}$ for two aminophenol ring of the ligand. The electronic spectrum of the ligand showed two bands at 223 and $306 \mathrm{~nm}$ that were assigned to $\pi-\pi^{*}$ of the aromatic rings and imine groups. The $[\mathrm{Mn}(\mathrm{BHBPDI}) \mathrm{Cl}]$ and $[\mathrm{Fe}(\mathrm{BHBPDI})) \mathrm{Cl}]$ complexes were synthesized similar to the literature. ${ }^{7,10,27}$ Elemental analysis, IR, UV-visible spectra and molar conductivity resulted in satisfactory data. The characteristic stretching frequencies at 1653 and $1640 \mathrm{~cm}^{-1}$ were attributed to the coordinated $-\mathrm{C}=\mathrm{N}$ of $\mathrm{Mn}$ and Fe complexes respectively. The electronic spectra were contained three bands at 223, 300 and $431 \mathrm{~nm}$ for [Mn(BHBPDI)Cl], and 
223, 300 and $422 \mathrm{~nm}$ for [Fe(BHBPDI)Cl] complexes. The first two bands of each complex were assigned to internal electronic transition of the coordinated ligand. The third bands of the spectra at 431 and $422 \mathrm{~nm}$ were suggested to be d-d electronic transitions of $\mathrm{Mn}$ and Fe-complexes respectively. The molar conductivities of the $\mathrm{Mn}(\mathrm{III})$ and $\mathrm{Fe}(\mathrm{III})$ complexes were 20.57 and $22.52 \mu \mathrm{S} / \mathrm{cm}$ that indicate both complexes are neutral. ${ }^{10,20,27}$

\section{Catalytic oxidative decarboxylation of arylacetic acids}

The catalytic activities of the complexes [Fe(BHBPDI)Cl] and $[\mathrm{Mn}(\mathrm{BHBPDI}) \mathrm{Cl}]$ were investigated for the oxidative decarboxylation of a variety of arylacetic acids according to typical procedure, using $(n-\mathrm{Bu})_{4} \mathrm{NIO}_{4}$ as oxidant in dichloromethane at room temperature. Before everything some parameters should be optimized. For the choice of the solvent, a typical reaction on diphenylacetic acid was performed using the $\mathrm{Mn}$ (III) or Fe(III) complex as catalyst in various solvents such as dichloromethane, chloroform, acetonitrile and methanol. The results summarized in the Table 1, showed that dichloromethane was the best solvent in our conditions. It is to be noted that in the absence of the catalysts the conversion of the diphenylacetic acid to the corresponding product was found to be low ( $<20 \%$ yield) even after prolonged reaction time that demonstrate the catalytic effect of the complexes in this reaction.

Table 1. The effect of solvent on catalytic oxidative decarboxylation of diphenylacetic acid

\begin{tabular}{ccc}
\hline Solvent & Reaction time(min.)/Mn(III) complex & Reaction time(min.)/Fe(III) complex \\
\hline $\mathrm{CH}_{2} \mathrm{Cl}_{2}$ & $70^{\mathrm{a}}$ & $170^{\mathrm{a}}$ \\
$\mathrm{CHCl}_{3}$ & $100^{\mathrm{a}}$ & $250^{\mathrm{a}}$ \\
$\mathrm{CH}_{3} \mathrm{CN}$ & $100^{\mathrm{b}}$ & $250^{\mathrm{b}}$ \\
$\mathrm{CH}_{3} \mathrm{OH}$ & $100^{\mathrm{b}}$ & $250^{\mathrm{b}}$ \\
\hline
\end{tabular}

${ }^{\mathrm{a}}$ The conversion was $100 \%$. ${ }^{\mathrm{b}}$ The reaction was not completed within time. ${ }^{\mathrm{c}}$ Refers to diphenylacetic acid $(1 \mathrm{mmol}),(n-\mathrm{Bu})_{4} \mathrm{NIO}_{4}(1 \mathrm{mmol})$, catalyst $(10 \%$ and $20 \%$ for $\mathrm{Mn}$ and $\mathrm{Fe})$ and imidazole $(0.2 \mathrm{mmol})$.

The effect of catalyst amounts was also investigated by performance of a typical oxidative decarboxylation on diphenylacetic in dichloromethane at room temperature (Table 2). The results showed $10 \%$ and $20 \%$ could be considered as optimal molar ratios for $\mathrm{Mn}$ (III) and $\mathrm{Fe}$ (III) complexes respectively in our conditions. The higher molar ratios were found not to have a considerable effect on the reaction progress.

One important aspect of these types of catalytic systems is the modification of rate by addition of an auxiliary base such as imidazole to the reaction mixture. As it will be seen in the scheme 2, imidazole stabilizes higher oxidation number of the metal ions (at oxo-compound, 3) for entrance to oxidation reaction. With this explanation, the amounts of $0.05,0.1,0.2$ and 0.3 mmol of imidazole were employed on typical decarboxylation of diphenylacetic acid and 0.2 mmol was found to be suitable. Low conversion $(<30-40 \%$ at the same times) was obtained in 
the absence or lower amounts of imidazole and higher amounts did not affect notably the reaction. Whereas the conversion reached to $100 \%$ in 70 and 170 min. with $0.2 \mathrm{mmol}$ of imidazole by $\mathrm{Mn}(\mathrm{III})$ and $\mathrm{Fe}(\mathrm{III})$ catalysts respectively. After the above investigation, the [ $\mathrm{Mn}^{\text {(III) }}$ or $\left.\mathrm{Fe}^{(\mathrm{III})}(\mathrm{BHBPDI}) \mathrm{Cl}\right] / \mathrm{imidazole} /(n \text {-Bu })_{4} \mathrm{NIO}_{4}$ catalytic system was used for the oxidative decarboxylation of a variety of arylacetic acids under optimum conditions that led to good to high yields at reasonable reaction times at room temperature. As shown in Table 3, the yields were between $75-95 \%$ and the principal products were carbonyl derivatives except for triphenylacetic acid (entry 2) that triphenylmethanol was obtained as product.

Table 2. The effect of catalyst amounts of $\mathrm{Mn}(\mathrm{III})$ or $\mathrm{Fe}(\mathrm{III})$ complexes in oxidative decarboxylation of diphenylacetic acid ${ }^{\mathrm{c}}$

\begin{tabular}{ccc}
\hline \%Molar ratio & Reaction time(min.)/ & Reaction time(min.)/ \\
(cat. to subs.) & Mn(III) complex & Fe(III) complex \\
\hline $5 \%$ & $120^{\mathrm{a}}$ & $320^{\mathrm{a}}$ \\
$10 \%$ & $70^{\mathrm{b}}$ & $200^{\mathrm{b}}$ \\
$15 \%$ & $65^{\mathrm{b}}$ & $180^{\mathrm{b}}$ \\
$20 \%$ & $60^{\mathrm{b}}$ & $170^{\mathrm{b}}$ \\
\hline
\end{tabular}

${ }^{\mathrm{a}}$ The reaction was not completed within time. ${ }^{\mathrm{b}}$ The conversion was $100 \%$. ${ }^{\mathrm{c}}$ Refers to diphenylacetic acid $(1 \mathrm{mmol}),(n-\mathrm{Bu})_{4} \mathrm{NIO}_{4}(1 \mathrm{mmol})$ and imidazole $(0.2 \mathrm{mmol})$.

Table 3. Catalytic oxidative decarboxylation of arylacetic acids in dichloromethane at room temperature $^{\mathrm{a}}$

Entry Arylacetic acid




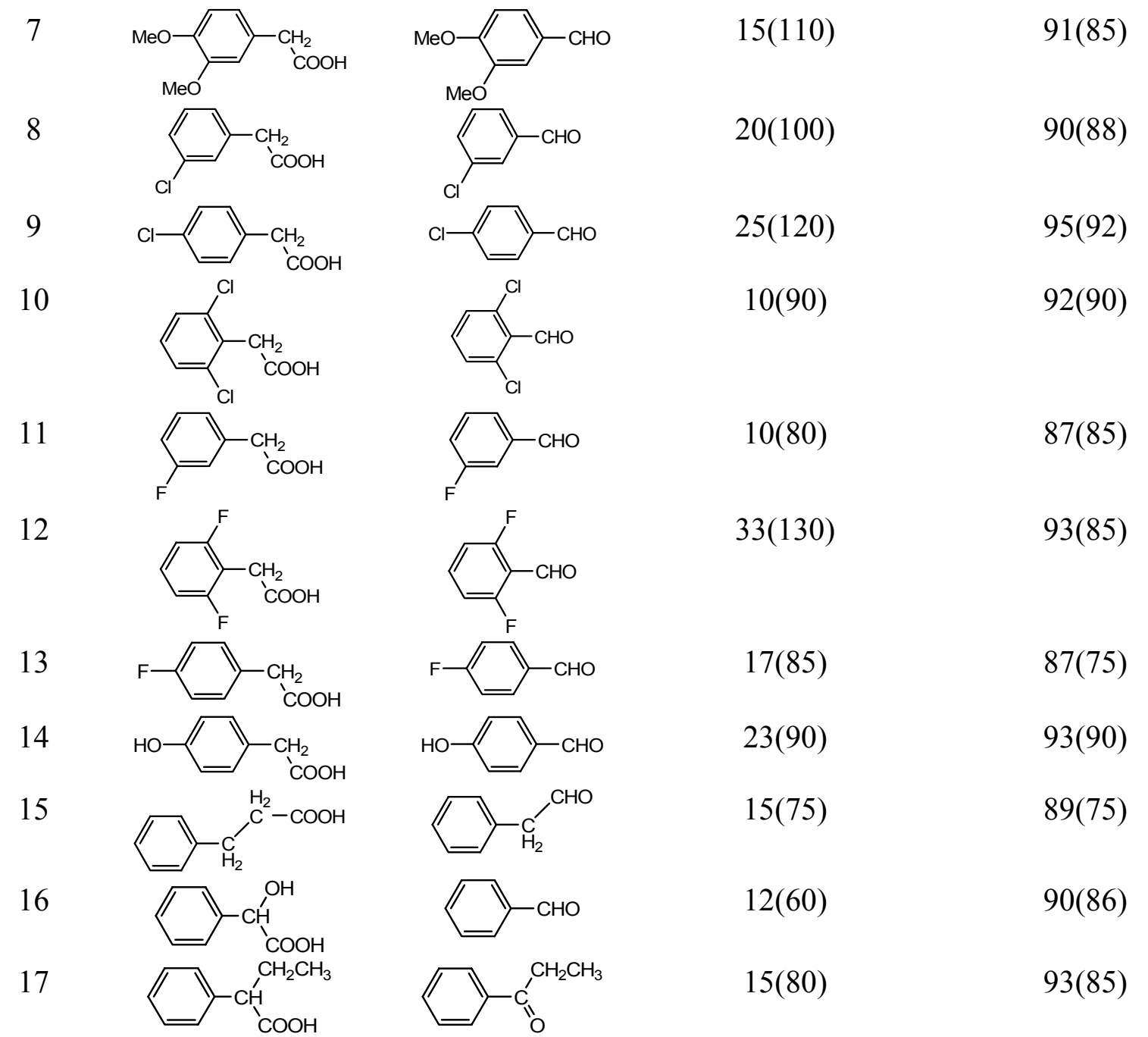

${ }^{a}$ Refers to arylacetic acid $(1 \mathrm{mmol}),(n-\mathrm{Bu})_{4} \mathrm{NIO}_{4}(1 \mathrm{mmol})$, molar ratios of $\mathrm{Mn}(\mathrm{III})$ and $\mathrm{Fe}(\mathrm{III})$ catalysts $\left(10 \%\right.$ and $20 \%$ molar ratios), and imidazole $(0.2 \mathrm{mmol}) .{ }^{b}$ Refers to isolated yields. ${ }^{\mathrm{c}} \mathrm{All}$ products are known and their physical and spectral data of them were compared with authentic samples.

\section{Proposed mechanism}

The catalytic cycle shown in the Scheme 2 is proposed for the oxidative decarboxylation of arylacetic acids using $\mathrm{Mn}(\mathrm{III})$-complex as the catalyst. When a light brown solution of $\left[\mathrm{Mn}^{(\mathrm{III})}(\mathrm{BHBPDI}) \mathrm{Cl}\right]$ (1) in dichloromethane is treated with tetrabutylamonium periodate, it immediately turns dark brown. Based on the literature, ${ }^{28}$ we have suggested the dark brown solution includes $\left[\mathrm{Mn}^{(\mathrm{V})}(\mathrm{O})(\mathrm{BHBPDI})\right]$ (3) intermediate (oxo-compound) as the important oxidant species in the oxidative decarboxylation. The substrate approaches to $\mathbf{3}$ and is finally decarboxylated to corresponding carbonyl derivative, $\mathrm{CO}_{2}$ and the $\mathbf{1}$ is regenerated. Returning the dark brown solution immediately to original light brown after the reaction supports this suggestion. According to Scheme 2 it is proposed that all arylacetic acids at first step are 
decarboxylated to corresponding primary (entries 3-15), secondary (entries 1 and 17) and/or tertiary (entry 2) alcohols and in the second step oxidized to carbonyl derivatives. Oxidative decarboxylation of triphenylacetic acid (entry 2) is stopped at first step including triphenylmethanol (a tertiary alcohol) because its further oxidation is very difficult under mild conditions. This observation is in agreement with proposed two step pathway of the oxidative decarboxylation. Also the proposed mechanism suggests the mandelic acid (entry 16) with one $\alpha-\mathrm{OH}$ is directly decarboxylated to benzaldehyde in one step oxidation. The $\mathrm{Mn}(\mathrm{III})$-complex exhibits a higher activity than Fe(III) analog system at the same conditions. This observation is supposed to be because of more severity of the Fe(III)-complex for the formation of oxocompound 3 with respect to $\mathrm{Mn}(\mathrm{III})$-complex.

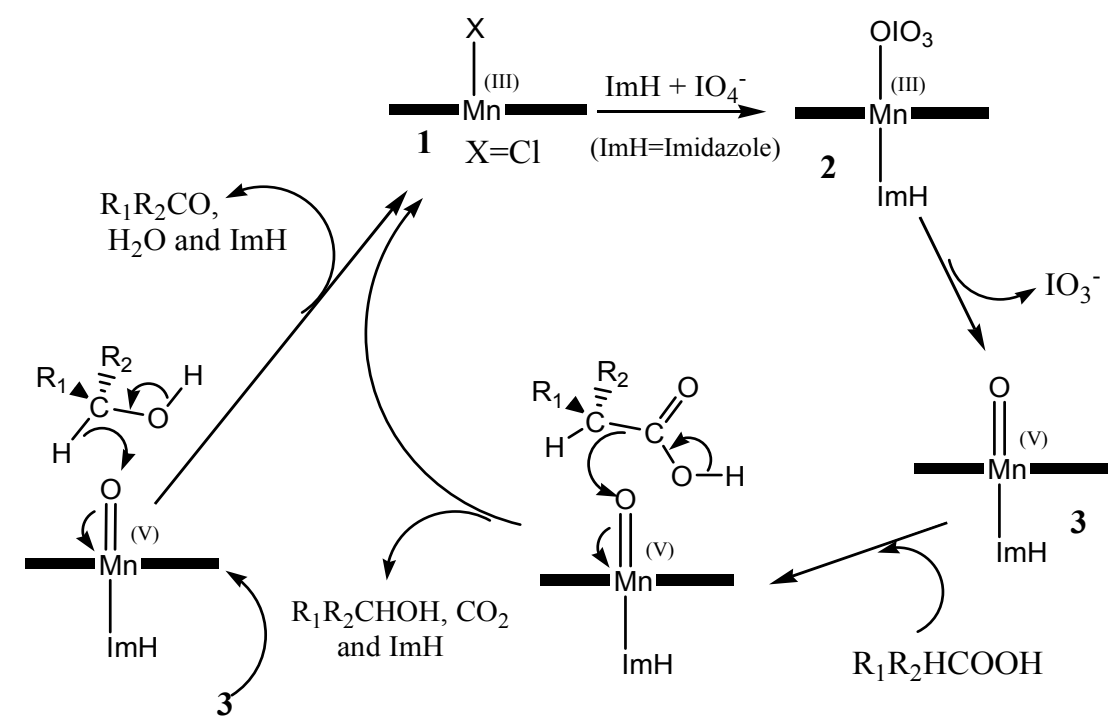

\section{Scheme 2}

\section{Conclusions}

In this paper we have reported the use of new Schiff base complexes of Iron(III) and Mn(III) as novel homogeneous catalyst in a convenient, efficient and practical method for the effective oxidative decarboxylation of a variety of arylacetic acids. The availability of the reagents, facile synthesis of the complexes, the easy work-up of products and the high yields make this method a useful alternative to literature procedures in this area. 


\section{Experimental Section}

General Procedures. Carboxylic acids were obtained from Merck or Fluka and used without further purification. The electronic absorption spectra were recorded with a JASCO UV-570 spectrophotometer. ${ }^{1} \mathrm{HNMR}$ spectra were obtained with a Brucker DPX-250 and $500 \mathrm{MHz}$ spectrometer. IR spectra were recorded on a FT-IR JASCO-680 spectrophotometer. Molar conductivity of complexes was measured by Metrohm 712 model. Elemental analyses (CNHS) of samples were performed using a CHNS-932 elemental analyzer by central instrumental laboratory of Tarbiat Moallem University of Tehran.

Preparation of bis(2-hydroxybenzene)phthaldiimine (BHBPDI). To a $25 \mathrm{~mL}$ ethanolic solution of 2-amonophenol $(5 \mathrm{mmol})$, phthaldialdehyde $(2.5 \mathrm{mmol})$ in ethanol $(25 \mathrm{~mL})$ was gradually added and the reaction mixture was refluxed. The progress of the reaction was monitored by TLC. After $8 \mathrm{~h}, 50 \mathrm{~mL}$ of cooled water was added to the reaction mixture and then the deep yellow precipitate was filtered off and washed with water and a ethanol/water mixture twice and the 1,2-Bis(2-hydroxybenzene)phtaldiimine was obtained in $76 \%$ yield. M.p. $\left({ }^{\circ} \mathrm{C}\right)=$ 117-120. Elemental analysis calculated (\%) $\mathrm{C}_{20} \mathrm{H}_{16} \mathrm{~N}_{2} \mathrm{O}_{2}$ : C 48.93, $\mathrm{H}$ 4.62; $\mathrm{N}$ 7.13. Found: $\mathrm{C}$, 49.27; H, 4.72; N, 6.96. Characteristic IR (KBr, cm $\left.{ }^{-1}\right): 3308$ (bs, vOH), 3061 (w, CH-aromatic), 2976 (w, CH-imine), 1634 (vs, -C=N(imine)), 1586 (s), 1493 (s), 1453 (s, -C=C-aromatic ring), 1331 (m), 1302 (m), 1274 (m), 1209 (m, -C-N), 1146 (m), 1123 (w), 1033 (m, C-O), 928 (w), $896(\mathrm{~m}), 747$ (s), $727(\mathrm{~s}), 657(\mathrm{~m}), 566(\mathrm{w}), 471(\mathrm{~m})$. UV-visible $\left(\mathrm{CH}_{2} \mathrm{Cl}_{2}, \lambda_{\max }\right): 223$ and $306 \mathrm{~nm}$. ${ }^{1} \mathrm{HNMR}$ (DMSO-d $\mathrm{d}_{6}$ ppm): 10.22 (bs, 1H), 8.88 (bs, 1H), 7.57 (m, 4H), 7.16 (m, 2H,), 6.93 (m, $2 \mathrm{H}), 6.61(\mathrm{~m}, 2 \mathrm{H})$ and $6.35(\mathrm{~m}, 4 \mathrm{H}) \mathrm{ppm}$.

Preparation of [Mn(BHBPDI)CI] and [Fe(BHBPDI)CI] complexes as the catalysts. Iron and manganese insertion into BHBPDI was achieved by heating the free-base BHBPDI (5 mmol) and $\mathrm{FeCl}_{3} .6 \mathrm{H}_{2} \mathrm{O}$ or $\mathrm{MnCl}_{2} .4 \mathrm{H}_{2} \mathrm{O}(5 \mathrm{mmol})$, respectively based on literature, ${ }^{7,10,27}$ under reflux, in ethanol, during 4-6 h. After cooling, cooled water was added to the reaction mixture and the brown solids were collected by filtration and washed twice with a small portion of ethanol/water mixture. [Fe(BHBPDI)Cl]. $\mathrm{H}_{2} \mathrm{O}$ : IR $\left(\mathrm{KBr}, \mathrm{cm}^{-1}\right)$ : 3206 (m, v $\left.\mathrm{H}_{2 \mathrm{O}}\right) 3067$ (w, CH-aromatic), 1640 (s, -C=N(imine)), 1597 (s), 1511 (s), 1498 (m), 1459 (m), 1395 (m), 1298 (m), 1210 (w), 1106 (w), $751(\mathrm{~s}), 473(\mathrm{w})$. UV-visible $\left(\mathrm{CH}_{2} \mathrm{Cl}_{2}, \lambda_{\max }\right): 223,300$ and $422 \mathrm{~nm}$. Elemental analysis calculated (\%) $\mathrm{C}_{20} \mathrm{H}_{16} \mathrm{ClFeN}_{2} \mathrm{O}_{3}$ : C, 56.70; H, 3.81; N, 6.61; Found: C, 57.45; H, 3.89; N, 6.49. M.p. $\left({ }^{\circ} \mathrm{C}\right)=$ $>300$ (dec.). $\Omega(\mathrm{MeOH})=20.57 \mu \mathrm{S} / \mathrm{cm}$. [Mn(BHBPDI)Cl]. $\mathrm{H}_{2} \mathrm{O}: \mathrm{IR}\left(\mathrm{KBr}, \mathrm{cm}^{-1}\right): 3276\left(\mathrm{~m}, v_{\mathrm{H} 2 \mathrm{O}}\right)$, 3063(w, CH-aromatic), 1654, (s, -C=N(imine)), 1593 (s), 1556 (w), 1496 (s), 1453 (s), 1343 (m), $1200(\mathrm{~m}), 1036$ (m), 851 (w), 814 (m), 745 (s), 704 (w), 584 (w), 476 (w). UV-visible $\left(\mathrm{CH}_{2} \mathrm{Cl}_{2}\right.$, $\left.\lambda_{\max }\right): 223,300$ and $431 \mathrm{~nm}$. Elemental analysis calculated $(\%) \mathrm{C}_{20} \mathrm{H}_{16} \mathrm{ClMnN}_{2} \mathrm{O}_{3}: \mathrm{C}, 56.82 ; \mathrm{H}$, 3.81; N, 6.63; Found: C 56.47, H 4.06, N 6.86. M.p. $\left({ }^{\circ} \mathrm{C}\right)=>340$ (dec.). $\Omega(\mathrm{MeOH})=22.52$ $\mu \mathrm{S} / \mathrm{cm}$. 


\section{Catalytic oxidative decarboxylation of arylacetic acids}

To the $\mathrm{Mn}$ (III) (0.1 mmol, 10\% molar ratio) or Fe(III) (0.2 mol, 20\% molar ratio) complex in dichloromethane $(20 \mathrm{~mL})$ were added imidazole $(0.2 \mathrm{mmol})$, the arylacetic acid $(1 \mathrm{mmol})$, and then tetrabutylamonium periodate $(1 \mathrm{mmol})$ was added. The reaction mixture was stirred at room temperature until TLC indicated the reaction was completed. The resulting solution was concentrated under reduced pressure to yield a residue, which was passed through a short pad of silica gel using ethyl acetate and $n$-hexane $(1: 2)$ as eluent to provide analytically pure product. All products are known and their physical and spectral data of them were compared with authentic samples.

\section{References}

1. Moutet, J. C.; Ourari, A. Electrochimica Acta 1997, 42, 2525.

2. Cunningham, I. D.; Danks, T. N.; Hay, J. N.; Hamerton, I.; Gunathilagan, S.; Janczak, C. $J$. Mol. Catal. A: Chem. 2002, 185, 25.

3. Maraval, V.; Ancel, J. E.; Meunier, B. J. Catal. 2002, 206, 349.

4. Olsen, M. H. N.; Salomao, G. C.; Drago, V.; Fernandes, C.; Horn J. A.; Cardozo Filho, L.; Antunes, O. A. C. J. Supercritical Fluids 2005, 34119.

5. Parton, R. F.; Vankelecom, I. F. J.; Casselman, M. J. A.; Bezoukhanova, C. P.; Uytterhoeven, J. B.; Jacob, P. A. Nature 1994, 370, 541.

6. Rosa, I. L. V.; Manso, C. M. C. P.; Serra, A. A.; Iamamoto, Y. J. Mol. Catal. A: Chem. 2000, 160, 199.

7. (a) Gomes, M. F. T.; Antunes, O. A. C.; Catal. Lett. 1996, 42, 213. (b) M. F. T. Gomes, O. A. C. Antunes, Catal. Lett. 1996, 38, 33.

8. Niassary, M. S.; Farzaneh, F.; Ghandi, M.; Turkian, L. J. Mol. Catal. A: Chem. 2000, 157, 183.

9. Gunter, M. J.; Turner, P. Coord. Chem. Rev. 1991, 108, 115.

10. (a) Miomandre, F.; Audebert, P.; Maumy, M.; Uhl, L. J. Electroanal. Chem. 2001, 66, 516.

(b) Hotchandani, S.; Ozdemir, U.; Nasr,C.; Allakhverdiev, S. I.; Karacan, N.; V. V. Klimov, P. V. Kamat, R. Carpentier, Bioelectrochem. Bioenerg. 1999, 48, 53. (c) A. Puglisi, G. Tabbi, G. Vecchio, J. Inorg. Biochem. 2004, 98, 969.

11. (a) Katsuki, T. In Jacobsen, E. N.; Pfaltz, A.; Yamamoto, H.; Eds. Comprehensive Asymmetric Catalysis, Vol. II, Springer-Verlag: Berlin, 1999, p 621. (b) Jacobsen, E. N.; Wu, M. H. In: Jacobsen, E. N.; Pfaltz, A.; Yamamoto H.; Eds. Comprehensive Asymmetric Catalysis, Vol. II, Springer-Verlag: Berlin, 1999, p 649. (c) Aggarwal, V. K.; In: Jacobsen, E. N.; Pfaltz, A.; Yamamoto, H. Eds. Comprehensive Asymmetric Catalysis, Vol. II, Springer- Verlag: Berlin, 1999, p 679.

12. Adam, W.; Humpf, H. U.; Roschmann, K. J.; Saha-Moller, C. R. J. Org. Chem. 2001, 66, 5796. 
13. Srinivasa, K.; Michaud, P.; Kochi, J. K. J. Am. Chem. Soc. 1986, 108, 2309.

14. Siddall, T. L.; Miyaura, N.; Huffman, J. C.; Kochi, J. K. J. Chem. Soc., Chem. Commun. 1983, 1185.

15. Ganeshpure, P. A.; Satish, S. J. Chem. Soc., Chem. Commun. 1988, 981.

16. Kim Y. I., Kim Y. H. Tetrahedron Lett. 1998, 39, 639.

17. Mohri, K.; Mamiya, J.; Kasahara, Y.; Isobe, K.; Tsuda, Y. Chem. Pharm. Bull. 1996, 44, 2218.

18. Habibi, M.H.; Farhadi, S. Tetrahedron Lett. 1999, 40, 2821.

19. Itoh, A.; Kodama, T.; Masaki, Y.; Inagaki, S. Chem. Pharm. Bull. 2006, 54, 1571.

20. Mirkhani, V.; Tangestaninejad, S.; Moghadam, M.; Karimian, Z. Bioorg. Med. Chem. Lett. 2003, 13, 3433 .

21. Mirkhani, V.; Tangestaninejad, S.; Moghadam, M.; Moghbel, M. Bioorg. Med. Chem. 2004, $12,903$.

22. Komuro, M.; Nagatsu, Y.; Higuchi, T.; Hirobe, M. Tetrahedron Lett. 1992, 33, 4949.

23. Komuro, M.; Higuchi, T.; Hirobe, M. Bioorg. Med. Chem. 1995, 3, 55.

24. Karimipour, Gh.; Momtazerozohori, M.; Karami, B. J. Chem. Res. 2006, 605.

25. Karami, B.; Montazerozohori, M.; Nasr-Esfahani, M. Heterocycles, 2005, 65, 2181.

26. Karami, B.; Montazerozohori, M.; Habibi, M. H. J. Chem. Res. 2006, 490.

27. (a) Geary, W. J. Coord. Chem. Rev. 1971, 7, 81. (b) Salomao, G. C.; Olsen, M. H. N.; Drago, V.;C.; Fernandes, L.; Filho,C.; Antunes, O. A. C.; Catalysis Communications 2007, $8,69$.

28. (a) Chellamani, A.; Alhaji, N. M. I.; Rajagopal, S.; Sevvel, R.; Srinivasan, C. Tetrahedron 1995, 51, 12677. (b) Chellamani, A.; Alhaji, N. M. I.; Rajagopal, S. J. Chem. Soc., Perkin Trans. 2 1997, 299. 